\title{
Efecto del color de la capa externa en la edad al primer parto, prolificidad e intervalo entre partos en un rebaño de ovejas de pelo en Campeche, México
}

\author{
Effect of coat color on age at first lambing, prolificacy and lambing interval \\ in a flock of hair ewes in Campeche, México \\ AM Andrade-Montoya ${ }^{a}$, G Torres-Hernández ${ }^{a^{*}}$, RD Martínez-Rojero ${ }^{\text {, }}$ \\ JM González-Camacho ${ }^{a}$, R González-Garduño ${ }^{\mathbf{c}}$, J Arece-García ${ }^{\mathrm{d}}$ \\ ${ }^{a}$ Colegio de Postgraduados-Campus Montecillo, Montecillo, México. \\ ${ }^{\mathrm{b} C}$ Colegio Superior Agropecuario del Estado de Guerrero, Iguala, México. \\ 'Unidad Regional Universitaria Sursureste, Universidad Autónoma Chapingo, Teapa, México. \\ dEstación Experimental de Pastos y Forrajes “Indio Hatuey”, Central España Republicana, Matanzas, Cuba.
}

\begin{abstract}
SUMMARY
The main objective of the study was to evaluate the effect of the ewe's coat color (brown, white, spotted, Blackbelly, and black) on age at first lambing (AFL, $n=578$ ), prolificacy (PRO, $n=475)$, and lambing interval ( $L I, n=438$ ) in a flock of hair sheep in Campeche, México. As a secondary objective, the effects of lambing year, lambing month, and the ewe's lambing number (primiparous, multiparous) were also evaluated. Data collected on reproductive characteristics during 5 years (2006-2010) from 340 ewes and their lambs were analysed. The sheep were managed under semi-extensive conditions; ewes and their lambs were allowed to graze during the day and were penned overnight. The statistical analysis was performed with the GLM procedure of the SAS statistical package utilizing fixed effects models. Overall least-squares means for AFL, PRO, and LI were $463.9 \pm 13.0$ days, $1.71 \pm 0.60$ lambs born per ewe lambing, and $295,7 \pm 17,9$ days, respectively. The ewe's coat color had a significant effect $(\mathrm{P} \leq 0.05)$ on AFL and LI; the lowest averages for AFL were for white $(435.8 \pm 1.4)$, brown $(438.5 \pm 2,4)$ and spotted $(439.7 \pm 3.6)$ ewes, while for LI the lowest averages were for spotted (284.9 \pm 6.9$)$, white $(288.8 \pm 1.6)$, and black $(291.7 \pm 5.8)$ ewes. Significant effects $((\mathrm{P} \leq 0.05)$ of lambing year, lambing month, and lambing number were found on the three characteristics. Due to their lowest averages being obtained at first lambing and lambing interval, it is concluded that white and spotted ewes in this flock should be preferred for a selection program in an attempt to decrease the average of both characteristics.
\end{abstract}

Key words: coat color, reproductive traits, hair sheep, humid tropic.

\section{RESUMEN}

El objetivo principal fue evaluar el efecto del color de la oveja (café, blanco, pinto, Blackbelly, y negro) en edad al primer parto (EPP, $\mathrm{n}=578)$, prolificidad (PRO, $n=475$ ) e intervalo entre partos (IEP, $n=438$ ) en un rebaño de ovinos de pelo en Campeche, México. De manera secundaria se evaluaron año de parto, mes de parto, y número de parto de la oveja (primíparas, multíparas). Se analizaron datos de características reproductivas de cinco años (2006-2010) de 340 ovejas y sus crías. El rebaño se manejó bajo condiciones semiextensivas; las ovejas y sus crías pastoreaban durante el día y se encerraban toda la noche. El análisis estadístico se efectuó con el procedimiento GLM del paquete estadístico SAS mediante modelos de efectos fijos.

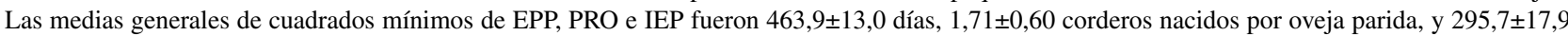
días, respectivamente. El color de la oveja influyó $(\mathrm{P} \leq 0,05)$ en EPP e IEP; los menores promedios para EPP fueron para las ovejas blancas $(435,8 \pm 1,4)$, café $(438,5 \pm 2,4)$ y pintas $(439,7 \pm 3,6)$, mientras que en IEP los menores promedios fueron para las ovejas pintas $(284,9 \pm 6,9$, blancas $(288,8 \pm 1,6)$, y negras $(291,7 \pm 5,8)$. Hubo efectos significativos $(\mathrm{P} \leq 0,05)$ de año de parto, mes de parto, y número de parto en las tres características. Por sus menores promedios obtenidos en edad al primer parto e intervalo entre partos, se concluye que en este rebaño las ovejas blancas y pintas deberían preferirse en un programa de selección en un intento por disminuir los promedios de ambas características.

Palabras clave: color capa externa, reproducción, ovinos de pelo, trópico húmedo.

\section{INTRODUCCIÓN}

El color de la capa externa de ovinos y caprinos es una característica cualitativa que ha sido utilizada por los productores como un criterio importante, entre otros,

Aceptado: 06.08.2014.

* 56230 Montecillo, México; glatohe@colpos.mx para decidir la compra de animales (Dossa y col 2008 ${ }^{1}$ y Terefe y col 2012), para evaluar características adaptativas de sementales sobre la base de medidas morfométricas y dimensiones escrotales (Adedeji y col 2011), para conocer la tolerancia a infecciones de nematodos gastrointestinales (Sanusi y col 2012), y para medir su tolerancia al calor en ambientes tropicales húmedos (McManus y col 2011

\footnotetext{
http://www.lrrd.org/lrrd20/5/doss20078.htm, consultado el 22 de agosto, 2012
} 
y Fadare y col 2012). En bovinos, el tipo y color de la capa externa tienen un efecto importante en la resistencia al calor (Finch y col 1984 y Turner 1984). Sin embargo, no se conoce bien todavía el efecto del color de la capa externa en diversas características productivas de ovinos de pelo, a pesar de que este conocimiento puede ser muy importante para determinar su adaptabilidad a las diversas condiciones ambientales, ya que la piel y el pelo en mamíferos terrestres, conjuntamente con el color, contribuyen a su adaptación climática (Gordon 1979). En un estudio con ovejas en Brasil (McManus y col 2009) y con cabras en la India (Acharya y col 1995) se encontró que los animales de color blanco resultaron mejor adaptados a las condiciones climáticas de estos países, comparados con animales de otras coloraciones. En la mayoría de las razas de ovinos en las que se ha estudiado la herencia del color se ha encontrado que el alelo $\mathrm{A}^{\mathrm{Wt}}$ es la causa de fenotipos blancos (Sponenberg 1997), comportándose el color blanco como una característica dominante en ovinos de lana (Renieri y col 2008) y codominante con el color café en ovinos de pelo ${ }^{2}$.

Estudios en ovinos de pelo que indiquen un efecto importante del color de la capa externa en características cuantitativas son muy escasos (Ebozoje e Ikeobi 1998 y Oke y Ogbonnaya $2011^{3}$ ), sobre todo en características reproductivas, y la tasa reproductiva es uno de los factores determinantes de la eficiencia económica y biológica de los sistemas de producción animal (Rubianes y Ungerfeld 2002). Sin embargo, las características reproductivas en los ovinos de pelo son afectadas por factores genéticos, fisiológicos y ambientales (Wildeus 1997), por lo que es importante evaluar sus efectos para conocer su magnitud y consecuente manejo en las poblaciones, sobre todo en lo que se refiere a mejoramiento genético. En un estudio efectuado en México con ovejas de pelo, GonzálezGarduño y col (2001) encontraron un efecto significativo $(\mathrm{P} \leq 0,01)$ del color de la capa externa de la oveja (de aquí en adelante: color de la oveja) en la edad al primer parto, en donde ovejas con la coloración Blackbelly tuvieron su primer parto a una edad más temprana $(\mathrm{P} \leq 0,05)$ que ovejas pintas, café, y blancas. Con el propósito de profundizar más en este conocimiento, el objetivo de este estudio fue analizar el efecto del color de la oveja en la edad al primer parto, prolificidad e intervalo entre partos en un rebaño de ovejas de pelo en Campeche, México. Como un objetivo secundario se analizó también el efecto del año de parto, mes de parto, y número de parto de la oveja en las mismas características.

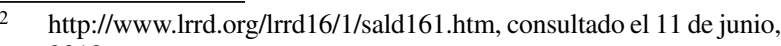
2012.

3 http://www.lrrd.org/lrrd23/2/oke23025.htm, consultado el 6 de septiembre, 2012
}

\section{MATERIAL Y MÉTODOS}

\section{ANIMALES Y MANEJO}

Para este estudio se contó con una base de datos reproductivos de ovejas de pelo de registro en un rancho en Campeche, México, ubicado a $19^{\circ} 43^{\prime} 47^{\prime \prime}$ latitud Norte y $90^{\circ} 21^{\prime}$ '03" longitud Oeste, y una altitud de $20 \mathrm{msnm}$. El clima de esta zona corresponde a la clasificación Aw, donde la precipitación anual oscila entre 1.000 y 1.200 $\mathrm{mm}$ y se distribuye de junio a octubre, y la temperatura media es de $25,8^{\circ} \mathrm{C}$ (García 1981). En este rancho se lleva a cabo un programa de manejo muy estricto para mejorar en los animales la conformación cárnica, los parámetros productivos y aumentar la prolificidad mediante la selección de hembras provenientes de partos múltiples al nacimiento. El rancho en 2006 contaba con 420 ovejas y 32 sementales y el objetivo es la venta de pie de cría y animales para abasto. Las ovejas pastorean diariamente durante seis horas en praderas de pastos Estrella de África (Cynodon plectostachyus) y Pará (Brachiaria mutica), mediante pastoreo rotacional. Las praderas están divididas con cercos eléctricos y cuentan con sistemas de riego, además de ser fertilizadas con nitrógeno y potasio. Por las tardes se alojan en corrales, donde reciben un alimento comercial (3\% de su peso vivo) compuesto por sorgo en grano, hojuela de maíz, pasta de soya, pasta de canola, melaza y sales minerales, alimento que contiene $16 \%$ de P.C. y 2,5 Mcal de E.M. $\mathrm{kg}^{-1}$ PV. Los sementales también reciben este alimento antes del inicio de la época de empadre. El manejo sanitario consiste en desparasitación contra parásitos gastrointestinales cada tres meses, vacunación anual de una sola dosis contra rabia paralítica y pasterelosis, así como la aplicación de un complejo vitamínico a hembras gestantes y sementales, antes del período de empadre. En este estudio se utilizaron los registros reproductivos de ovejas de pelo recolectados en 5 años (2006 a 2010). Las crías se destetan entre 80 y 100 días de edad con un peso de 17 a $20 \mathrm{~kg}$.

\section{ANÁLISIS ESTADÍSTICO}

Las variables dependientes analizadas fueron edad al primer parto (EPP, días), prolificidad (PRO, número de crías nacidas por oveja parida) e intervalo entre partos (IEP, días). Para calcular el intervalo entre partos se utilizaron las fechas entre un primero y segundo parto, que correspondieron a los años 2006 y 2007. Se efectuó un análisis de varianza utilizando modelos de efectos fijos. En los modelos de las tres variables dependientes se analizaron los efectos de color de la oveja (CO: café, blanco, pinto, Blackbelly, y negro), como también las variables de tipo ambiental año de parto (AP) y mes de parto (MP). En el modelo para PRO, además de los efectos de año y mes de parto, se incluyó el número de parto (NP) de la oveja (primípara, multípara). Los datos se analizaron usando el 
procedimiento GLM del paquete estadístico SAS (SAS 1999) y, en los casos donde procedía, se efectuó la comparación entre medias de subclases con la prueba de Tukey. Para el análisis de estos datos se hizo la suposición de una distribución normal en las 3 variables dependientes. Un análisis preliminar indicó que no existieron interacciones significativas $(P \geq 0,05)$ de primer orden.

\section{RESULTADOS}

La EPP fue influenciada por color de la oveja $(\mathrm{P} \leq 0,05)$, además de año y mes de parto ( $\mathrm{P} \leq 0,01$, cuadro 1$)$. Los promedios de edad al primer parto fueron similares en las ovejas de colores café, blanco y pinto, cuyos promedios fueron menores que los de las ovejas con las coloraciones Blackbelly y negro (cuadro 2).

No se encontró un efecto significativo $(\mathrm{P} \geq 0,05)$ de color de la oveja en PRO; esta solamente fue influenciada por año y mes de parto, y número de parto $(\mathrm{P} \leq 0,01$, cuadro 1$)$.

El IEP tuvo influencias significativas de color de la oveja $(\mathrm{P} \leq 0,01)$ y año de parto $(\mathrm{P} \leq 0,05)$. Los promedios más cortos correspondieron a las ovejas con colores blanco, pinto y negro (cuadro 2).

Cuadro 1. Significancia estadística de variables que influyen en la edad al primer parto (EPP), prolificidad (PRO), e intervalo entre partos (IEP) en un rebaño de ovejas de pelo en Campeche, México.

Statistical significance of variables that influence age at first lambing (EPP), prolificacy (PRO), and lambing interval (IEP) in a flock of hair ewes in Campeche, México.

\begin{tabular}{lccc}
\hline Fuente de variación & EPP & PRO & IEP \\
\hline Color de la oveja & $*$ & $\mathrm{~ns}$ & $* *$ \\
Año de parto & $* *$ & $* *$ & $*$ \\
Mes de parto & $* *$ & $* *$ & $\mathrm{~ns}$ \\
Número de parto & ---- & $* *$ & ---- \\
\hline
\end{tabular}

$* *: \mathrm{P} \leq 0,01, *: \mathrm{P} \leq 0,05$, ns: no significativo.

\section{DISCUSIÓN}

Por su importancia económica, es muy deseable que la edad al primer parto ocurra lo más temprano posible (Álvarez y Andrade 2008). Los resultados para EPP favorecieron a las ovejas blancas, café y pintas. Si estos resultados fueran de aplicación general para los ovinos de pelo, los promedios menores encontrados en este estudio beneficiarían a los productores en el trópico de México, quienes en su mayoría tienen preferencia por tener en sus rebaños ovejas café y blancas ${ }^{2}$. En esta misma referencia ${ }^{2}$ se postuló que en el rebaño estudiado los colores blanco y pinto eran lo mismo, en virtud a la alta correlación entre ambos $(r=0,94, P \leq 0,01)$. En otro rebaño de ovinos de pelo en México, González-Garduño y col (2001) encontraron que el promedio de EPP para ovejas con la coloración Blackbelly fue menor (503 días, $\mathrm{P} \leq 0,05$ ) que en las ovejas de colores blanco, café, y pinto, cuyo promedio del grupo fue 562 días. Por lo anterior, se puede interpretar que este resultado es característico de cada rebaño, y no de los ovinos de pelo en general, por lo que es necesaria más investigación en relación con esta variable. Respecto del color negro en ovinos de pelo, Ponzoni (1992) indica que este color es el resultado de un gen recesivo. En cabras West African Dwarf se encontró que, aunque no tuvo un efecto significativo $(P \geq 0,05)$, la edad al primer parto se incrementó al disminuir la intensidad en la pigmentación (Ebozoje e Ikeobi 1998).

Dickerson (1996) señaló que la importancia de la prolificidad está relacionada con su efecto en la eficiencia y potencial de rentabilidad de la producción de corderos para el abasto. Por otra parte, es la característica responsable de la mayor parte de la variación en el comportamiento reproductivo de especies multíparas (Pérez-Enciso y Bidanel 1997) y la que tiene el mayor potencial para cambio por selección (Bradford 2002). Hay información muy escasa en la literatura acerca del efecto del color en la prolificidad. González-Garduño y col (2001) tampoco encontraron un efecto significativo del color en esta característica. Si el

Cuadro 2. Medias de cuadrados mínimos (media \pm error estándar) de edad al primer parto (EPP), prolificidad (PRO), e intervalo entre partos (IEP) de acuerdo al color de la oveja en un rebaño de ovinos de pelo en Campeche, México.

Least-squares means (mean \pm standard error) of age at first lambing (EPP), prolificacy (PRO), and lambing interval (IEP) according to the ewe's color in a flock of hair sheep in Campeche, México.

\begin{tabular}{|c|c|c|c|c|c|c|}
\hline \multirow{2}{*}{$\begin{array}{l}\text { Color de la oveja } \\
\text { Café }\end{array}$} & \multicolumn{2}{|c|}{$\begin{array}{c}\text { EPP } \\
\text { (días) }\end{array}$} & \multicolumn{2}{|c|}{$\begin{array}{c}\text { PRO } \\
\left(\mathrm{N}^{\mathrm{o}} \text { de crías nacidas }\right. \\
\text { por oveja parida })\end{array}$} & \multicolumn{2}{|c|}{$\begin{array}{c}\text { IEP } \\
\text { (días) }\end{array}$} \\
\hline & $108 *$ & $438,5 \pm 3,5 \mathrm{a}$ & 83 & $1,70 \pm 0,08 \mathrm{a}$ & 78 & $310,6 \pm 5,8 \mathrm{~b}$ \\
\hline Blanco & 158 & $435,8 \pm 2,4 \mathrm{a}$ & 137 & $1,69 \pm 0,02 \mathrm{a}$ & 120 & $288,8 \pm 3,3$ a \\
\hline Pinto & 102 & $439,7 \pm 3,6 \mathrm{a}$ & 80 & $1,71 \pm 0,08 \mathrm{a}$ & 74 & $284,9 \pm 5,6 \mathrm{a}$ \\
\hline Blackbelly & 112 & $468,5 \pm 3,4 \mathrm{~b}$ & 95 & $1,74 \pm 0,06 \mathrm{a}$ & 88 & $302,6 \pm 5,1 \mathrm{~b}$ \\
\hline Negro & 98 & $536,9 \pm 5,3 \mathrm{c}$ & 80 & $1,72 \pm 0,08 \mathrm{a}$ & 78 & $291,7 \pm 5,8 \mathrm{a}$ \\
\hline
\end{tabular}

a, b, c: medias con diferente literal en la misma columna difieren $(\mathrm{P} \leq 0,05)$ *: número de observaciones. 
color blanco se originara de una raza catalogada como prolífica, como por ejemplo la Finnsheep (Maijala 1996), esto indicaría que tendríamos que tratar la prolificidad como una característica cuantitativa, originada por muchos pares de genes; sin embargo, se ha postulado que en ovinos de pelo el color blanco se debe a un solo gen (Ponzoni 1992). En ovinos de Islandia se encontró que ovejas que tienen el alelo $\mathrm{A}^{\mathrm{Wt}}$ (que produce el color blanco) son en promedio $15 \%$ menos fecundas que aquellas que no lo tienen (Adalsteinsson 1975), y además son más estacionales (Dyrmundsson y Adalsteinsson 1980). En caprinos West African Dwarf, Ebozoke e Ikeobi (1998) encontraron que cabras de color negro tuvieron una prolificidad mayor que las café, blancas, y pintas, tanto al nacimiento como al destete de las crías.

El intervalo entre partos comprende el lapso entre el parto y el servicio fecundo más el período de gestación, que tiene muy escasa variación (González 1993), y es posiblemente el mejor parámetro para evaluar la eficiencia reproductiva, ya que combina los efectos de otras características reproductivas (Valencia-Zarazúa y González-Padilla 1983). De acuerdo con el resultado para esta característica, los productores que tienen ovejas de pelo de colores blanco, pinto, y negro pueden ser beneficiados, en virtud a que estas ovejas tuvieron los promedios menores. Este resultado difiere del obtenido por González-Garduño y col (2001), quienes no encontraron un efecto significativo ( $P$ $\geq 0,05$ ) del color en el IEP, por lo que, aunado al resultado en la edad al primer parto, se refuerza más la hipótesis de que el efecto del color de la oveja en estas características es más un efecto de rebaño que de raza. Sería interesante investigar en el rebaño estudiado si el resultado del color blanco es debido a su mejor adaptación en los ambientes cálidos, como lo señalaron McManus y col (2009) en ovejas Santa Inês de Brasil, como también investigar si entre los colores blanco y pinto se confirma la alta correlación encontrada en otro rebaño de ovinos de pelo ${ }^{2}$.

Como se mencionó en la metodología, el intervalo entre partos en el presente estudio se calculó entre el primero y segundo parto. En relación con lo anterior, es interesante mencionar las conclusiones de un trabajo acerca de intervalo entre partos efectuados por investigadores de la Universidad de Guelph, Canadá ${ }^{4}$, derivado de un análisis con varias razas de ovinos, y que tiene relación con la edad al primer parto y la prolificidad. De este trabajo los autores concluyeron: a) el intervalo entre el primero y segundo parto no pareció tener relación alguna con edad al primer parto, por lo que la selección para reducir el intervalo entre partos no afectaría la edad al primer parto, b) el intervalo entre el primero y segundo parto tiene una correlación pequeña pero positiva con la prolificidad; por tanto la selección para reducir el intervalo entre partos tendería a reducir la prolificidad, c) finalmente, para

4 http://www.uoguelph.ca/ jtosh/lambint2, consultado el 4 de febrero, 2014. reducir el intervalo entre partos se recomienda el uso de un índice de selección, de tal manera que se obtenga un balance entre ambas características.

\section{PROMEDIOS GENERALES DE FACTORES AMBIENTALES}

Los promedios generales de EPP, PRO e IEP fueron $463,9 \pm 13,0$ días, $1,71 \pm 0,60$ crías nacidas por oveja parida, y $295,7 \pm 17,9$ días, respectivamente. Aunque no obedece al objetivo principal del presente estudio, resalta el promedio obtenido en PRO, cuyo valor es el más alto que se ha reportado a la fecha en ovejas de pelo bajo manejo semiextensivo en México, ya que trabajos en este país (Segura y col 1996 y Macedo y Alvarado 2005) indican promedios en el rango de 1,13 a 1,55, que son valores similares a los de otros países, como el de 1,16 en Colombia ${ }^{5}, 1,2$ en Venezuela (Dickson y col 2004), y 1,35 en Cuba (Guevara $y$ col 1986). El promedio de 1,71 en PRO en el presente trabajo se atribuye principalmente al proceso de selección que se lleva a cabo en este rancho al utilizar ovejas nacidas de partos múltiples, aunado al buen manejo general del rebaño, especialmente en el aspecto de alimentación. Este procedimiento de selección fue utilizado con bastante éxito en Nueva Zelanda (Clarke 1972) y Australia (Turner 1978), logrando incrementar con bastante éxito la prolificidad en ovinos Romney Marsh y Merino, respectivamente.

\section{REFERENCIAS}

Acharya RM, UD Gupta, JP Sehgal, M Singh. 1995. Coat characteristics of goats in relation to heat tolerance in the hot tropics. Small Rumin Res 18, 245-248.

Adalsteinsson S. 1975. Depressed fertility in Icelandic sheep caused by a single colour gene. Ann Gen Sel Anim 7, 445-447.

Adedeji TA, MO Ozoje, SO Peters, LO Ojedapo, OA Sanusi. 2011. Effect of coat color and wattle genes on the morphometric characteristics and scrotal dimensions of traditionally reared West African Dwarf (WADI) bucks. Int J Agril Env Biotech 4, 157-162.

Álvarez L, S Andrade. 2008. El efecto macho reduce la edad al primer estro y ovulación en corderas Pelibuey. Arch Zoot 57, 91-94.

Bradford GE. 2002. Selection for reproductive efficiency. Sheep and Goat Res J 17, 6-10.

Clarke JN. 1972. Current levels of performance in the Ruakura fertility flock of Romney sheep. Proc New Zealand Soc Anim Prod 32, 99-111.

Dickerson GE. 1996. Economic importance of prolificacy in sheep. In: Fahmy MH (ed). Prolific Sheep. CAB International, Wallingford, UK, Pp 205-213.

Dickson L, G Torres-Hernández, R D’aubeterre, O García. 2004. Factores que influyen en el intervalo entre partos y la prolificidad de un hato de carneros Pelibuey en Venezuela. Rev Cubana Ciencia Agric 38, 13-17.

Dyrmundsson OR, S Adalsteinsson. 1980. Coat-colour gene suppresses sexual activity in Icelandic sheep. $J$ Heredity 71, 363-364.

Ebozoje MO, CON Ikeobi, 1998. Colour variation and reproduction in the West African Dwarf (WAD) goats. Small Rumin Res 27, 125-130.

Fadare AO, SO Peters, A Yakubu, AO Sonibare, MA Adeleke, MO Ozoje, IG Imumorin. 2012. Physiological and haematological indices suggest

5 http://lrrd.cipav.org.co/lrrd3/1/mejia.htm, consultado el 15 de julio, 2012. 
superior heat tolerance of white-coloured West African Dwarf sheep in the hot humid tropics. Trop Anim Hlth Prod 45, 157-165.

Finch VA, IL Bennett, CR Holmes. 1984. Coat color in cattle: effect on thermal balance, behavior and growth, and relationship with coat type. J Agric Sci 102, 141-147.

García ME. 1981. Modificación del Sistema de Clasificación Climática de Köppen. Instituto de Geografía, Universidad Nacional Autónoma de México, México, D.F., México.

González SC. 1993. Comportamiento reproductivo de ovejas y cabras tropicales. Rev Científica FCV-LUZ III, 173-196.

González-Garduño R, G Torres-Hernández, CM Becerril-Pérez, P DíazRivera. 2001. Relación del color del pelaje y factores ambientales con características reproductivas en ovejas tropicales. Agrociencia $35,41-50$

Gordon MS. 1979. Fisiología Animal. Principios y Adaptaciones. CICSA, México, D.F., México.

Guevara GA, A Piñeiro, R Cardoso, P Sánchez, CV Zayaz. 1986. Comparación entre las razas Suffolk, Barriguinegra y tres variedades de Pelibuey en varios caracteres. Rev Cubana Prod Anim 2, 173-176.

Macedo R, A Alvarado. 2005. Efecto de la época de monta sobre la productividad de ovejas Pelibuey bajo dos sistemas de alimentación en Colima, México. Arch Zoot 54, 51-62

Maijala K. 1996. The Finnsheep. In: Fahmy MH (ed.). Prolific Sheep. CAB International, Wallingford, UK, Pp 10-46.

McManus C, GR Paludo, H Louvandini, R Gugel, LCB Sasaki, SR Paiva. 2009. Heat tolerance in Brazilian sheep: Physiological and blood parameters. Trop Anim Hlth Prod 41, 95-101.

McManus C, H Louvandini, R Gugel, LCB Sasaki, E Bianchini, FEM Bernal, SR Paiva, TP Paim. 2011. Skin and coat traits in sheep in Brazil and their relation with heat tolerance. Trop Anim Hlth Prod 43, 121-126.

Pérez-Enciso M, JP Bidanel. 1997. Selection for litter size components: a critical review. Gen Sel Evol 29, 483-496.
Ponzoni RW. 1992. Genetic Improvement of Hair Sheep in the Tropics. Animal Production and Health Paper 101. FAO, Rome, Italy.

Renieri C, A Valbonesi, V La Manna, M Antonini, Lauvergne. 2008. Inheritance of coat color in Merino sheep. Small Rumin Res 74, 23-29.

Rubianes E, R Ungerfeld. 2002. Perspectivas de la investigación sobre reproducción ovina en América Latina en el marco de las actuales tendencias productivas. Arch Latinoam Prod Anim 10, 117-125.

Sanusi AO, SO Peters, AO Sonibare, IG Imumorin, MO Ozoje. 2012. Preliminary association of coat color types and tolerance to Haemonchus contortus infection in West African Dwarf sheep. $J$ Appl Anim Res 40, 1-7.

SAS (Statistical Analysis System). 1999. SAS User's Guide. Version 8. Cary, NC, USA.

Segura JC, L Sarmiento, O Rojas. 1996. Productivity of Pelibuey and Blackbelly ewes in Mexico under extensive management. Small Rumin Res 21, 57-62.

Sponenberg DP. 1997. Genetics of colour and hair texture. In: Piper L, Ruvinsky A (eds). The Genetics of Sheep. CAB International, Wallingford, UK, Pp 51-86.

Terefe G, T Teklue, K Shimelis. 2012. Study on common phenotypic traits for purchasing sheep and their association with price and purpose of purchase in four markets of East Showa Zone. Ethiop Vet $J 16,15-26$.

Turner HN. 1978. Selection for reproduction rate in Australian Merino sheep: Direct responses. Aust J Agric Res 29, 327-350.

Turner HG. 1984. Variation in rectal temperature of cattle in a tropical environment and its relation to growth rate. Anim Prod 38, 417-427.

Valencia-Zarazúa M, E González-Padilla. 1983. Pelibuey sheep in Mexico. In: Hair Sheep of Western Africa and the Americas. A Genetic Resource for the Tropics. West View Press, Boulder, USA, Pp 55-73.

Wildeus S. 1997. Hair sheep genetic resources and their contribution to diversified small ruminant production in the United States. J Anim Sci 75, 630-640. 
